\title{
Agreement between milk fat, protein, and lactose observations collected from the Dairy Herd Improvement Association (DHIA) and a real-time milk analyzer
}

\author{
K. Kaniyamattam and A. De Vries ${ }^{1}$ \\ Department of Animal Sciences, University of Florida, Gainesville 32611
}

\begin{abstract}
The objective of this study was to quantify the agreement between AfiLab real-time milk analyzer (Afimilk, Kibbutz Afikim, Israel) measures for fat, protein, and lactose based on near-infrared spectrum light scattering, and those collected on Dairy Herd Improvement Association (DHIA) test days and measured with the Bentley 2000 analyzer (Bentley Instruments Inc., Chas$\mathrm{ka}, \mathrm{MN}$ ), which uses mid-infrared spectrum light. The AfiLab data were collected twice daily for each milking cow in the herd at 12-h intervals from the double-12 parlor at the University of Florida Dairy Unit (Hague, FL) from January 2010 to December 2011. Bentley data for the 23 DHIA test days in 2010 and 2011 were also obtained. Approximately 450 cows were tested each month. Tested milk was collected during 1 milking each month, alternating monthly between morning and evening milkings. AfiLab data were matched with Bentley fat and protein ( $\mathrm{n}=10,273 ; 23$ test days $)$ and lactose $(\mathrm{n}=6,741 ; 16$ test days). Overall means \pm standard deviations (SD) of monthly mean Bentley fat, protein, and lactose were $3.74 \pm 0.80 \%, 3.06 \pm 0.37 \%$, and 4.76 $\pm 0.30 \%$, respectively. Overall means \pm SD of monthly mean AfiLab minus Bentley observations were -0.08 \pm 0.12 percentage points $(\mathrm{PP})$ for fat $(\mathrm{n}=23), 0.02 \pm$ $0.11 \mathrm{PP}$ for protein $(\mathrm{n}=23)$, and $-0.02 \pm 0.08 \mathrm{PP}$ for lactose $(\mathrm{n}=16)$. Overall means $\pm \mathrm{SD}$ of monthly within-test-day SD of AfiLab minus Bentley observations were $0.66 \pm 0.11 \mathrm{PP}$ for fat, $0.27 \pm 0.03 \mathrm{PP}$ for protein, and $0.26 \pm 0.03 \mathrm{PP}$ for lactose. Overall means $\pm \mathrm{SD}$ of the corresponding monthly correlations were $0.59 \pm$ 0.09 for fat, $0.67 \pm 0.04$ for protein, and $0.46 \pm 0.08$ for lactose. Averaging the AfiLab observations from up to 6 milkings before and after the test-day milking improved the agreement for protein and lactose but not for fat. Averaging the 13 protein observations improved the mean difference to $0.01 \pm 0.10 \mathrm{PP}$ and the SD of the difference to $0.23 \pm 0.03 \mathrm{PP}$. The correlation increased
\end{abstract}

Received November 7, 2013.

Accepted January 22, 2014.

${ }^{1}$ Corresponding author: devries@ufl.edu to $0.78 \pm 0.04$. Averaging the 13 lactose observations improved the SD of the difference to $0.23 \pm 0.02 \mathrm{PP}$, but the mean of the difference decreased to $-0.03 \pm$ 0.09 PP. The correlation for lactose increased to 0.55 \pm 0.05. Generally, AfiLab slightly overestimated low Bentley components and underestimated high Bentley components. We found some evidence for a systematic cow effect on lack of agreement for lactose, but not for fat and protein. The agreement between AfiLab and Bentley observations was better for protein and lactose than that for fat. Combinations of AfiLab observations from various milkings improved the agreement for protein and lactose. AfiLab real-time milk analyzers may be helpful to estimate DHIA observations.

Key words: agreement, Dairy Herd Improvement Association (DHIA), AfiLab, milk component

\section{INTRODUCTION}

The composition of the milk of individual cows is an indicator of its economic value as well as the cow's health and nutritional status (Aernouts et al., 2011). The availability of daily observations of milk components, either at the herd or individual level, as a dairy herd management and nutritional monitoring tool has been advocated (Wiggans, 1994; Studer, 1998). For example, daily milk fat content could be used to evaluate the forage-to-concentrate ratio of the diet (Murphy et al., 2000). The daily protein content could be used as an indicator of adequate dietary energy supply (Svennersten-Sjaunja et al., 1997) and daily lactose content might be useful to detect mastitis (Auldist et al., 1995; Svennersten-Sjaunja et al., 1997). The fat-toprotein ratio is an indicator of ketosis (Duffield et al., 1997). Rapid detection of changes in milk composition is important so that action can be taken as soon as needed.

The most common source of individual milk composition observations is DHIA, which provides monthly or less frequent analyses of individual cows' milk for dairy farmers that participate in one of the milk testing programs. Typically, the fat and protein contents in the milk are determined. In addition, the milk may be 
tested for SCC, MUN, lactose, solids other than fat, disease pathogens, or indicators of pregnancy such as pregnancy-associated glycoprotein. Milk components vary from milking to milking, depending on the time between milkings, DIM, and season (Quist et al., 2008; Pavel and Gavan, 2011). Additional variation over time is expected. A DHIA measure obtained once per month may therefore not closely represent the average or sum of a cow's milk components for that month.

Recently, real-time analysis of milk components per cow per milking has become more widely available, primarily through the implementation of automatic milking systems (Rotz et al., 2003). One such real-time individual cow milk analyzer is the AfiLab system (Afimilk, Kibbutz Afikim, Israel), which is implemented per parlor stall. Each AfiLab uses near-infrared spectroscopy (NIR) for on-line milk analysis (Tsenkova et al., 1999). The advantages of an NIR system over other systems are that they are speedy and give nondestructive on-line measurements (Schmilovitch et al., 2000a). Accuracy may be reduced, however (Tsenkova et al., 2000). The AfiLab system provides observations of milk fat, protein, and lactose components, in addition to the amount of blood. No peer-reviewed studies have documented the agreement between measures of milk components obtained from DHIA laboratories and the AfiLab system. Reasonable agreement between both systems would indicate that the milk components obtained by AfiLab may be useful measures of a cow's milk components.

The objective of this study was to document the agreement between fat, protein, and lactose observations obtained from routine monthly DHIA testing and AfiLab observations per cow per milking. The effect of season, parity, DIM, and parlor stall on agreement was investigated. To adjust for possible bias, the accuracy of estimation models for DHIA components using a combination of AfiLab observations was researched. Finally, systematic bias in estimations for individual cows was investigated. The first hypothesis was that AfiLab observations are helpful estimators of single DHIA observations. The second hypothesis was that a combination of AfiLab observations would improve agreement with DHIA observations.

\section{MATERIALS AND METHODS}

\section{Farm Management}

Milk production and component data were obtained from January 2010 to December 2011. All data originated at the University of Florida's Dairy Unit located in Hague, Florida, where approximately 450 Holstein cows were housed in mostly sand-bedded freestalls and fed a TMR twice daily. All lactating cows received the same TMR, but rations were frequently changed during the course of the study as part of routine herd management. Cows were milked in 2 milking sessions per day with 12-h intervals in a double-12 herringbone milk parlor. An AfiLab real-time milk analyzer (Afimilk) was installed in each of the 24 milk parlor stalls in September 2008. Milk yields and percentages of fat, protein, and lactose were recorded per cow per milking (morning and evening). The Afifarm management program (Afimilk) was used for daily herd management and data storage, including AfiLab and DHIA results. No animal use protocol was necessary for this study because only routinely collected field data were used.

\section{DHIA Observations}

Cows were tested monthly by DHIA. Monthly milk testing followed the a.m.-p.m. scheme (Wiggans, 1994) where cows were alternately tested in either the morning or afternoon milking session by trained DHIA technicians. Milk was collected into standard DHIA sample vials. All DHIA samples were sent to and analyzed in the DHIA certified laboratory in Belleview, Florida. The laboratory used the Bentley 2000 mid-infrared (MIR) method (Bentley Instruments Inc., Chaska, MN) to analyze fat (BFAT), protein (BPRO), and lactose (BLAC) percentages in the milk of each sample. The Bentley method provides quantitative observations from the MIR wavebands (2 to $15 \mu \mathrm{m}$ ). The accuracy of the Bentley method has been described elsewhere (Tsenkova et al., 2000; Kaylegian et al., 2006).

The BFAT and BPRO were obtained from DHIA as part of the routine return of milk test results and were automatically stored in and later retrieved from Afifarm. The BLAC observations were obtained directly from the laboratory because they are not routinely returned by DHIA. Milk components obtained from DHIA represent average daily values calculated using correction factors depending on the milking interval (Wiggans, 1986), but because the milking intervals were $12 \mathrm{~h}$ for all test days in the study, the DHIA observations were identical to the milk components of the milking session in which they were measured. Consequently, the milk components obtained from the Bentley and AfiLab systems could be directly compared.

\section{AfiLab Observations}

The AfiLab system provided observations of percentages of milk fat, protein, and lactose per cow per milking and were automatically stored in and later retrieved from Afifarm. The technology used in AfiLabs for milk component measurement is multivariate analysis of 
NIR milk spectra, extracting data from the nonspecific lines based on light scattering principles described by Schmilovitch et al. (2000b). AfiLab is designed for accurate estimates in the range of 2 to $6 \%$ fat and 2 to $5 \%$ protein (A. Arazi, Afimilk, Israel, personal communication). Milk components outside these ranges are estimated less accurately. No range for accuracy is given for lactose. During milking, the AfiLab equipment measures milk components per $200 \mathrm{~mL}$ of milk that flows through the machine but reports only the average of the approximately 70 observations $(15 \mathrm{~kg})$ per cow's milking.

Each AfiLab was zero-set (calibrated) monthly and remotely as part of routine maintenance by Afimilk using the BFAT, BPRO, and BLAC observations of the latest DHIA milk test. The goal of zero-setting was to eliminate the bias per stall. Zero-setting involved resetting parameters in the AfiLab software based on detection of internal device problems or maintenance problems in the parlor, including bias introduced by dirt and cleaning. All zero-settings were performed between the morning and afternoon milking sessions. Zero-setting took place on average $13 \mathrm{~d}$ after the DHIA milk test.

\section{Data Set}

Twelve variables were calculated from the AfiLab observations for each cow and test day as follows. The AfiLab observations of percentage milk fat, protein, and lactose on the same milking session as the DHIA test-day milking session are referred to as AFAT1, APRO1, and ALAC1, respectively. In addition, the averages of the AfiLab observations of 3 and 13 consecutive milkings with the DHIA test milking being the median milking were also calculated for each milk component. For example, for the evening milk test on January 17, 2010, the AfiLab observations on the morning milking of January 17, 2010, and morning milking of January 18, 2010, were used to calculate AFAT3, APRO3, and ALAC3 as the average of the 3 observations. The AFAT13, APRO13, and ALAC13 were similarly calculated from 13 milkings around the test-day milking, and AFAT7, APRO7, and ALAC7 were calculated as the average of the 3 morning milkings before and 3 morning milkings after the test-day milking, if the test-day milking was in the morning including the test-day milking itself, or the 3 evening milkings before and after the test-day milking if the test-day milking was an evening milking, including the test-day milking itself.

The observations obtained from each DHIA milk test (BFAT, BPRO, and BLAC) were paired with the 12 AfiLab variables of the same milking and cow. AfiLab observations were not available for the milk test on July 20, 2010. AfiLab observations were occasionally not available for some cows on other test days due to data capture errors. The 3 AfiLab observations (fat, protein, lactose) were either all present or all absent for a cow for a milking. Descriptive statistics are presented in Table 1.

Differences (E) in milk component observations per cow and test day were calculated as the AfiLab observation minus the Bentley observation; for example, EFAT1 = AFAT1 - BFAT. Collectively, 12 differences (4 for fat, 4 for protein, and 4 for lactose) were calculated per cow and test date.

The data set incorporated 10,571 observations, including both BFAT and BPRO measured on 23 test days for an average of 460 cows per test day. In addition, BLAC data were only available for 16 test days (n $=6,861$ ). The data set included 10,273 observations of AFAT1, APRO1, and ALAC1. All AFAT1 and APRO1 observations had a paired BFAT and BPRO observation, respectively. However, 3,532 ALAC1 observations did not have a paired BLAC observation. The numbers of observations for EFAT3, EPRO3, and ELAC3 were $9,912,9,885$, and 6,668 , respectively. The numbers of observations for EFAT7, EPRO7, and ELAC7 were $7,754,7,681,5,310$, and the numbers of observations for EFAT13, EPRO13, and ELAC13 were 7,310, 7,189, and 5,134 , respectively.

Milk yield in the test-day session as determined by the Afimilk milk meters (AMY1) and by DHIA (BMY) were added per cow per test day, as well as parity (1 or $2+$ ), calving date, and parlor stall number (1 to 24 ). The BMY was the average of the 7 daily milk yields.

\section{Statistical Analysis}

Differences between Bentley and AfiLab observations were summarized by the mean (= bias), standard deviation (SD), mean absolute error (MAE), and root mean square error (RMSE); $\mathrm{MAE}=\Sigma\left|E_{i}\right| / n$ and RMSE $=\sqrt{ }\left[\left(E_{i}\right)^{2} / n\right]$, where $n$ is the number of cows per test day and $E_{i}$ is the difference between the AfiLab and Bentley observation of cow $i$, respectively. The RMSE is a combined estimate of both expectation and dispersion and therefore is a more comprehensive measure of estimation error than the mean, SD, and MAE. The RMSE is a traditional measure of accuracy of an estimation method (De Vries and Feleke, 2008). If there is no bias, then the SD equals the RMSE. Pearson correlations were also calculated. Results from this analysis are presented in Table 2 .

The effects of BFAT, BPRO, BLAC, BMY, DIM, parity (fixed), parlor stall (fixed), and test day (fixed) 
Table 1. Summary statistics of milk test fat, protein, lactose, and yield on the DHIA test day (Bentley 2000 analyzer, Bentley Instruments Inc., Chaska, MN) and corresponding AfiLab (Afimilk, Kibbutz Afikim, Israel) observations ${ }^{1}$

\begin{tabular}{|c|c|c|c|c|c|c|c|c|c|c|c|c|c|c|}
\hline \multirow[b]{2}{*}{$\begin{array}{l}\text { Milk test date } \\
\text { (month/day/ } \\
\text { year) }\end{array}$} & \multirow[b]{2}{*}{ Session $^{2}$} & \multicolumn{5}{|c|}{ Number of observations } & \multicolumn{8}{|c|}{ Mean \pm SD } \\
\hline & & BFAT & BPRO & BLAC & BMY & $\begin{array}{c}\text { AFAT1, } \\
\text { APRO1, } \\
\text { ALAC1, } \\
\text { AMY1 }\end{array}$ & BFAT & AFAT1 & BPRO & APRO1 & BLAC & ALAC1 & BMY & AMY1 \\
\hline $1 / 17 / 2010$ & 2 & 471 & 471 & 425 & 450 & 445 & $3.86 \pm 0.78$ & $3.64 \pm 0.58$ & $3.11 \pm 0.34$ & $3.10 \pm 0.31$ & $4.79 \pm 0.27$ & $4.67 \pm 0.23$ & $15.85 \pm 5.37$ & $15.33 \pm 5.40$ \\
\hline $2 / 15 / 2010$ & 1 & 464 & 464 & 433 & 463 & 456 & $3.65 \pm 0.92$ & $3.74 \pm 0.58$ & $3.08 \pm 0.31$ & $3.10 \pm 0.29$ & $4.74 \pm 0.26$ & $4.80 \pm 0.24$ & $16.89 \pm 5.64$ & $17.43 \pm 5.91$ \\
\hline $3 / 15 / 2010$ & 2 & 464 & 464 & - & 459 & 448 & $3.78 \pm 0.84$ & $3.52 \pm 0.54$ & $3.06 \pm 0.32$ & $3.11 \pm 0.31$ & - & $4.69 \pm 0.16$ & $16.17 \pm 5.04$ & $16.36 \pm 5.46$ \\
\hline $4 / 19 / 2010$ & 1 & 451 & 451 & 417 & 448 & 445 & $3.66 \pm 0.86$ & $3.52 \pm 0.57$ & $2.97 \pm 0.30$ & $3.12 \pm 0.32$ & $4.74 \pm 0.34$ & $4.63 \pm 0.28$ & $15.87 \pm 5.48$ & $16.57 \pm 5.51$ \\
\hline $5 / 17 / 2010$ & 2 & 447 & 447 & - & 432 & 429 & $3.83 \pm 0.97$ & $3.57 \pm 0.58$ & $2.99 \pm 0.32$ & $2.94 \pm 0.32$ & - & $4.78 \pm 0.22$ & $16.29 \pm 5.33$ & $15.59 \pm 5.09$ \\
\hline $6 / 21 / 2010$ & 1 & 456 & 456 & 407 & 446 & 445 & $3.68 \pm 0.71$ & $3.69 \pm 0.58$ & $2.98 \pm 0.38$ & $2.89 \pm 0.33$ & $4.74 \pm 0.28$ & $4.72 \pm 0.20$ & $14.75 \pm 4.65$ & $15.36 \pm 4.96$ \\
\hline $8 / 16 / 2010$ & 1 & 439 & 439 & 396 & 438 & 432 & $3.65 \pm 0.70$ & $3.54 \pm 0.64$ & $2.96 \pm 0.36$ & $3.00 \pm 0.36$ & $4.66 \pm 0.30$ & $4.62 \pm 0.27$ & $14.04 \pm 4.99$ & $14.96 \pm 5.23$ \\
\hline $9 / 20 / 2010$ & 2 & 405 & 405 & 380 & 401 & 399 & $3.66 \pm 0.70$ & $3.70 \pm 0.57$ & $3.05 \pm 0.36$ & $2.86 \pm 0.30$ & $4.70 \pm 0.26$ & $4.86 \pm 0.19$ & $14.52 \pm 4.36$ & $14.62 \pm 4.54$ \\
\hline $10 / 18 / 2010$ & 1 & 421 & 421 & - & 415 & 413 & $3.75 \pm 0.84$ & $3.70 \pm 0.52$ & $3.10 \pm 0.35$ & $3.09 \pm 0.25$ & - & $4.71 \pm 0.17$ & $15.61 \pm 4.91$ & $15.81 \pm 5.20$ \\
\hline $11 / 15 / 2010$ & 2 & 455 & 455 & 408 & 454 & 449 & $3.81 \pm 0.79$ & $3.66 \pm 0.57$ & $3.13 \pm 0.39$ & $3.04 \pm 0.28$ & $4.74 \pm 0.31$ & $4.70 \pm 0.20$ & $13.90 \pm 5.04$ & $14.25 \pm 5.26$ \\
\hline $12 / 13 / 2010$ & 1 & 464 & 464 & 444 & 462 & 460 & $3.94 \pm 0.99$ & $3.90 \pm 0.61$ & $3.11 \pm 0.42$ & $3.10 \pm 0.28$ & $4.78 \pm 0.31$ & $4.77 \pm 0.18$ & $15.02 \pm 5.56$ & $15.66 \pm 5.83$ \\
\hline $1 / 17 / 2011$ & 2 & 491 & 491 & 457 & 471 & 469 & $4.07 \pm 0.92$ & $3.73 \pm 0.61$ & $3.10 \pm 0.38$ & $3.29 \pm 0.27$ & $4.78 \pm 0.32$ & $4.55 \pm 0.19$ & $16.38 \pm 6.05$ & $15.32 \pm 5.84$ \\
\hline $2 / 7 / 2011$ & 1 & 490 & 490 & & 480 & 480 & $3.72 \pm 0.88$ & $3.64 \pm 0.57$ & $3.05 \pm 0.39$ & $3.33 \pm 0.30$ & & $4.51 \pm 0.21$ & $15.62 \pm 5.42$ & $16.56 \pm 5.82$ \\
\hline $3 / 13 / 2011$ & 2 & 458 & 458 & - & 455 & 454 & $3.65 \pm 0.64$ & $3.54 \pm 0.48$ & $3.00 \pm 0.31$ & $3.09 \pm 0.24$ & - & $4.70 \pm 0.15$ & $15.63 \pm 4.99$ & $15.88 \pm 5.13$ \\
\hline $4 / 11 / 2011$ & 1 & 505 & 505 & 477 & 505 & 499 & $3.57 \pm 0.68$ & $3.53 \pm 0.53$ & $3.01 \pm 0.34$ & $3.03 \pm 0.27$ & $4.74 \pm 0.36$ & $4.75 \pm 0.19$ & $14.94 \pm 5.53$ & $15.78 \pm 5.67$ \\
\hline $5 / 8 / 2011$ & 2 & 500 & 500 & 474 & 485 & 485 & $3.66 \pm 0.79$ & $3.61 \pm 0.53$ & $3.03 \pm 0.32$ & $3.06 \pm 0.26$ & $4.81 \pm 0.27$ & $4.79 \pm 0.19$ & $15.39 \pm 5.14$ & $15.45 \pm 5.25$ \\
\hline $6 / 13 / 2011$ & 1 & 466 & 466 & 440 & 465 & 464 & $3.53 \pm 0.70$ & $3.57 \pm 0.57$ & $3.03 \pm 0.34$ & $3.06 \pm 0.25$ & $4.82 \pm 0.25$ & $4.78 \pm 0.20$ & $15.15 \pm 5.61$ & $15.90 \pm 5.96$ \\
\hline $7 / 10 / 2011$ & 2 & 463 & 463 & - & 461 & 459 & $3.71 \pm 0.68$ & $3.62 \pm 0.52$ & $3.15 \pm 0.55$ & $3.11 \pm 0.26$ & - & $4.72 \pm 0.21$ & $14.55 \pm 5.23$ & $14.37 \pm 5.18$ \\
\hline $8 / 8 / 2011$ & 1 & 455 & 455 & 417 & 449 & 445 & $3.61 \pm 0.79$ & $3.62 \pm 0.57$ & $3.06 \pm 0.37$ & $3.21 \pm 0.25$ & $4.78 \pm 0.28$ & $4.75 \pm 0.21$ & $14.41 \pm 5.19$ & $15.70 \pm 5.50$ \\
\hline $9 / 11 / 2011$ & 2 & 427 & 427 & - & 427 & 418 & $3.65 \pm 0.77$ & $3.58 \pm 0.51$ & $3.14 \pm 0.40$ & $3.06 \pm 0.24$ & - & $4.75 \pm 0.16$ & $14.32 \pm 4.82$ & $14.81 \pm 5.03$ \\
\hline $10 / 10 / 2011$ & 1 & 452 & 452 & 424 & 452 & 361 & $3.83 \pm 0.82$ & $3.84 \pm 0.58$ & $3.05 \pm 0.39$ & $3.17 \pm 0.28$ & $4.77 \pm 0.33$ & $4.76 \pm 0.22$ & $14.54 \pm 5.23$ & $14.55 \pm 5.94$ \\
\hline $11 / 6 / 2011$ & 2 & 467 & 467 & 434 & 467 & 462 & $4.16 \pm 0.88$ & $4.13 \pm 0.59$ & $3.16 \pm 0.42$ & $3.08 \pm 0.26$ & $4.79 \pm 0.30$ & $4.72 \pm 0.22$ & $14.78 \pm 5.38$ & $13.84 \pm 5.26$ \\
\hline $12 / 12 / 2011$ & 1 & 460 & 460 & 428 & 460 & 456 & $3.68 \pm 0.86$ & $3.79 \pm 0.60$ & $3.14 \pm 0.40$ & $3.13 \pm 0.25$ & $4.76 \pm 0.29$ & $4.79 \pm 0.18$ & $16.13 \pm 5.90$ & $16.13 \pm 5.96$ \\
\hline Mean (all) & & 460 & 460 & 429 & 454 & 447 & $3.74 \pm 0.80$ & $3.67 \pm 0.57$ & $3.06 \pm 0.37$ & $3.09 \pm 0.28$ & $4.76 \pm 0.30$ & $4.72 \pm 0.20$ & $15.25 \pm 5.26$ & $15.49 \pm 5.43$ \\
\hline
\end{tabular}

$\rightarrow$ BFAT, BPRO, BLAC = percentage fat, protein, and lactose from the Bentley analysis; BMY is the milk yield recorded by DHIA (7-d average, kg/d); AFAT1, APRO1, ALAC1 兽. are the percentage fat, protein, and lactose from the AfiLab analysis, respectively; AMY1 is the actual milk yield recorded during the session of the milk test (kg/d).

ஸे ${ }^{2} 1=$ morning milking session, 2 = evening milking session.

$\frac{\Omega}{\Phi}$. $\quad{ }^{3}$ Overall mean of 23 monthly means; AfiLab observations for the milk test date of $7 / 20 / 2010$ were not available. 
Table 2. Summary measures of agreement between milk test fat, protein, and lactose from the Bentley (Bentley 2000 analyzer, Bentley Instruments Inc., Chaska, MN) observations and AfiLab (Afimilk, Kibbutz Afikim, Israel) observations on the DHIA test day for the same milking ${ }^{1,2}$

\begin{tabular}{|c|c|c|c|c|c|c|c|c|c|c|c|c|c|c|c|}
\hline \multirow{2}{*}{$\begin{array}{l}\text { Milk test date } \\
\text { (month/day/year) }\end{array}$} & \multicolumn{5}{|c|}{ EFAT1 = AFAT1 - BFAT } & \multicolumn{5}{|c|}{$\mathrm{EPRO} 1=\mathrm{APRO} 1-\mathrm{BPRO}$} & \multicolumn{5}{|c|}{$\mathrm{ELAC} 1=\mathrm{ALAC} 1-\mathrm{BLAC}$} \\
\hline & RMSE & MAE & Mean & SD & Corr. & RMSE & MAE & Mean & SD & Corr. & RMSE & MAE & Mean & SD & Corr. \\
\hline $1 / 17 / 2010$ & 0.65 & 0.49 & -0.22 & 0.62 & 0.63 & 0.24 & 0.18 & 0.00 & 0.24 & 0.74 & 0.32 & 0.23 & -0.11 & 0.30 & 0.26 \\
\hline $2 / 15 / 2010$ & 0.72 & 0.55 & 0.10 & 0.72 & 0.62 & 0.24 & 0.18 & 0.02 & 0.24 & 0.68 & 0.24 & 0.18 & 0.07 & 0.23 & 0.49 \\
\hline $3 / 15 / 2010$ & 0.76 & 0.56 & -0.26 & 0.71 & 0.54 & 0.27 & 0.21 & 0.05 & 0.26 & 0.66 & - & - & - & - & - \\
\hline 4/19/2010 & 0.78 & 0.53 & -0.14 & 0.77 & 0.48 & 0.32 & 0.24 & 0.15 & 0.28 & 0.57 & 0.33 & 0.24 & -0.09 & 0.32 & 0.35 \\
\hline $5 / 17 / 2010$ & 0.87 & 0.57 & -0.26 & 0.83 & 0.50 & 0.26 & 0.20 & -0.06 & 0.25 & 0.68 & - & - & - & - & - \\
\hline $6 / 21 / 2010$ & 0.58 & 0.40 & 0.00 & 0.58 & 0.61 & 0.29 & 0.22 & -0.09 & 0.27 & 0.70 & 0.25 & 0.20 & -0.02 & 0.25 & 0.37 \\
\hline 8/16/2010 & 0.78 & 0.55 & -0.11 & 0.77 & 0.34 & 0.32 & 0.25 & 0.04 & 0.32 & 0.59 & 0.28 & 0.22 & -0.03 & 0.28 & 0.51 \\
\hline $9 / 20 / 2010$ & 0.48 & 0.35 & 0.05 & 0.48 & 0.72 & 0.33 & 0.26 & -0.19 & 0.27 & 0.65 & 0.29 & 0.22 & 0.15 & 0.24 & 0.45 \\
\hline $10 / 18 / 2010$ & 0.69 & 0.48 & -0.05 & 0.69 & 0.57 & 0.26 & 0.19 & 0.00 & 0.26 & 0.66 & - & - & - & - & - \\
\hline $11 / 15 / 2010$ & 0.72 & 0.50 & -0.16 & 0.70 & 0.50 & 0.29 & 0.22 & -0.09 & 0.27 & 0.72 & 0.25 & 0.19 & -0.05 & 0.24 & 0.51 \\
\hline $12 / 13 / 2010$ & 0.88 & 0.60 & -0.04 & 0.87 & 0.48 & 0.30 & 0.22 & -0.02 & 0.30 & 0.68 & 0.27 & 0.20 & -0.01 & 0.27 & 0.49 \\
\hline 1/17/2011 & 0.83 & 0.57 & -0.35 & 0.76 & 0.56 & 0.34 & 0.27 & 0.21 & 0.27 & 0.67 & 0.35 & 0.30 & -0.23 & 0.27 & 0.46 \\
\hline $2 / 7 / 2011$ & 0.67 & 0.43 & -0.08 & 0.66 & 0.66 & 0.42 & 0.35 & 0.29 & 0.30 & 0.66 & - & - & - & - & - \\
\hline 3/13/2011 & 0.51 & 0.39 & -0.11 & 0.50 & 0.63 & 0.26 & 0.21 & 0.10 & 0.24 & 0.64 & - & - & - & - & - \\
\hline 4/11/2011 & 0.51 & 0.36 & -0.05 & 0.50 & 0.68 & 0.25 & 0.19 & 0.02 & 0.25 & 0.68 & 0.26 & 0.20 & 0.00 & 0.26 & 0.53 \\
\hline $5 / 8 / 2011$ & 0.59 & 0.41 & -0.07 & 0.58 & 0.67 & 0.23 & 0.18 & 0.03 & 0.23 & 0.71 & 0.25 & 0.19 & -0.02 & 0.25 & 0.47 \\
\hline 6/13/2011 & 0.53 & 0.38 & 0.04 & 0.53 & 0.66 & 0.23 & 0.18 & 0.04 & 0.23 & 0.75 & 0.22 & 0.18 & -0.03 & 0.22 & 0.49 \\
\hline 7/10/2011 & 0.54 & 0.40 & -0.09 & 0.53 & 0.64 & 0.34 & 0.19 & -0.03 & 0.34 & 0.69 & - & - & - & - & - \\
\hline 8/8/2011 & 0.61 & 0.42 & 0.02 & 0.61 & 0.65 & 0.31 & 0.24 & 0.15 & 0.27 & 0.70 & 0.25 & 0.19 & -0.02 & 0.25 & 0.48 \\
\hline 9/11/2011 & 0.60 & 0.44 & -0.06 & 0.60 & 0.61 & 0.29 & 0.23 & -0.06 & 0.28 & 0.64 & - & - & - & - & - \\
\hline $10 / 10 / 2011$ & 0.65 & 0.47 & -0.02 & 0.66 & 0.62 & 0.31 & 0.24 & 0.10 & 0.29 & 0.68 & 0.27 & 0.21 & -0.01 & 0.27 & 0.52 \\
\hline 11/6/2011 & 0.76 & 0.47 & -0.03 & 0.76 & 0.52 & 0.34 & 0.25 & -0.09 & 0.33 & 0.66 & 0.26 & 0.20 & -0.05 & 0.25 & 0.54 \\
\hline 12/12/2011 & 0.72 & 0.49 & 0.11 & 0.72 & 0.57 & 0.31 & 0.23 & -0.02 & 0.31 & 0.66 & 0.27 & 0.19 & 0.05 & 0.27 & 0.40 \\
\hline Mean $(\text { all })^{3}$ & 0.67 & 0.47 & -0.08 & 0.66 & 0.59 & 0.29 & 0.22 & 0.02 & 0.27 & 0.67 & 0.27 & 0.21 & -0.02 & 0.26 & 0.46 \\
\hline $\mathrm{SD}$ (all) & 0.12 & 0.07 & 0.12 & 0.11 & 0.09 & 0.05 & 0.04 & 0.11 & 0.03 & 0.04 & 0.03 & 0.03 & 0.08 & 0.03 & 0.08 \\
\hline
\end{tabular}

${ }^{1}$ EFAT1, EPRO1, ELAC1 are the differences in fat, protein, and lactose observations per cow and test day (calculated as the AfiLab observation minus the Bentley observation); AFAT1, APRO1, ALAC1 are the percentage fat, protein, and lactose from the AfiLab analysis, respectively; BFAT, BPRO, BLAC are the percentage fat, protein, and lactose from the Bentley analysis, respectively.

${ }^{2} \mathrm{RMSE}=$ root mean squared error, $\mathrm{MAE}=$ mean absolute error, Corr. $=$ correlation

${ }^{3}$ Overall mean of 23 monthly means. AfiLab observations for the milk test date of $7 / 20 / 2010$ were not available. 
Table 3. Factors affecting differences in fat, protein, and lactose obtained from Bentley (Bentley 2000 analyzer, Bentley Instruments Inc., Chaska, MN) and AfiLab (Afimilk, Kibbutz Afikim, Israel) analyzers ${ }^{1}$

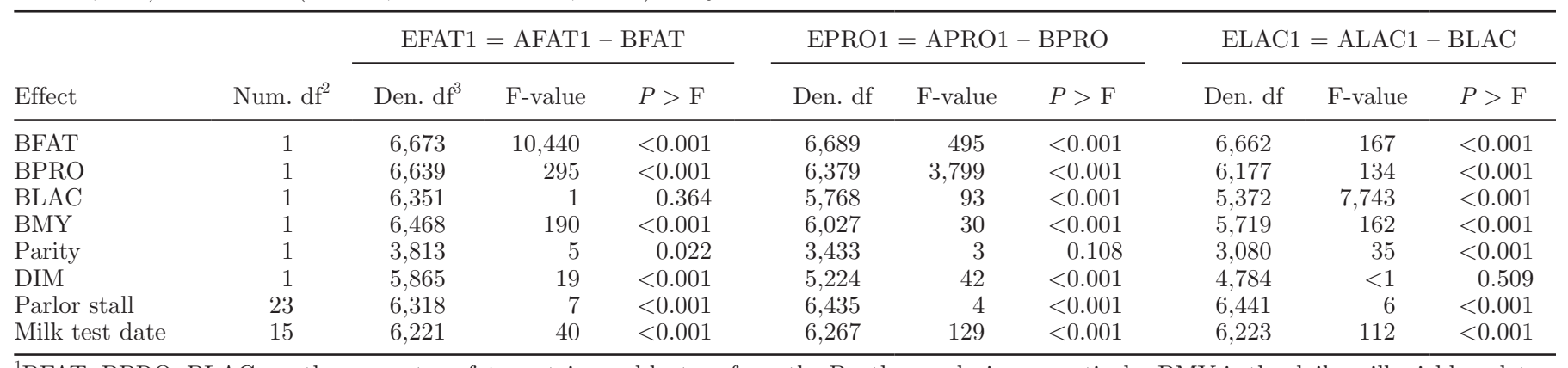

${ }^{1}$ BFAT, BPRO, BLAC are the percentage fat, protein, and lactose from the Bentley analysis, respectively; BMY is the daily milk yield as determined by DHIA; AFAT1, APRO1, ALAC1 are the percentage fat, protein, and lactose from the AfiLab analysis, respectively; EFAT1, EPRO1, and ELAC1 are calculated as the AfiLab minus the Bentley observations.

${ }^{2}$ Numerator degrees of freedom.

${ }^{3}$ Denominator degrees of freedom.

on EFAT1, EPRO1, and ELAC1 were investigated using mixed models. The covariance structure used was compound symmetry, the subject effect was cow, the estimation method was REML, and test day was a repeated effect. Degrees of freedom were estimated using the Kenward-Roger method. Results from this analysis are presented in Table 3.

The AfiLab observations tended to overestimate low milk components and underestimate high milk components as measured by the Bentley method. Therefore, simple regression equations were developed from the AfiLab variables to investigate if the Bentley milk components could be estimated more accurately (models $\mathrm{B}$ to $\mathrm{F}$ ). The regression models were of the form Bentley observation $=b_{0}+b_{1} \times$ AfiLab observation. The test-day data from 2010 were used to develop the equations, which then were used to estimate the 2011 Bentley observations. The fit statistics calculated were residual variance, $\mathrm{R}^{2}$, -2 RES log-likelihood, Akaike information criterion (AIC), and Bayesian information criterion (BIC). Differences in estimated and observed milk components for 2010 and 2011 were summarized by the mean, standard deviation, MAE, and RMSE. Results from these analyses are presented in Tables 4 , 5 , and 6 .

The final analysis investigated whether the AfiLab observation would typically over- or underestimate the milk components of certain cows, regardless of the actual level of their milk components. To analyze this, means of the estimation errors per cow $(\mathrm{n} \leq 23)$ from the regression model with the AfiLab observation of the same milking (model $\mathrm{C}$ ) were tested with a $t$-test; for example, fat error $=\left(b_{0}+b_{1} \times\right.$ AFAT1 $)-$ BFAT. The distribution of $P$-values from the $t$-tests was investigated.

All data analyses were carried out in Excel 2010 (Microsoft Corp., Redmond, WA) for the calculation of means and SD. The Mixed procedure in SAS version 9.3 (SAS Institute Inc., Cary, NC) was used for model development and analysis. The GLM procedure was used to calculate $\mathrm{R}^{2}$ in Tables 4,5 , and 6 .

\section{RESULTS}

Summary statistics of the DHIA and AfiLab observations for each of the 23 test dates are shown in Table 1. The number of observations varied between months and for different DHIA components within months. The number of BFAT and BPRO observations (mean of 460) was greater than the number of AFAT and APRO observations (mean of 447) in all months. The correlations between monthly means of BFAT and BPRO, $\mathrm{BFAT}$ and BLAC, and $\mathrm{BPRO}$ and BLAC were 0.47 $(P=0.02), 0.27(P=0.32)$, and $0.43(P=0.10)$, respectively. The overall mean and SD of the 23 monthly means of BMY and AMY1 were 15.25 \pm 5.26 and 15.49 $\pm 5.43 \mathrm{~kg} /$ cow per milking session. The overall mean and SD of the monthly means for BFAT and AFAT1 were $3.74 \pm 0.80 \%$ and $3.67 \pm 0.57 \%$, respectively. For protein, these results were $3.06 \pm 0.37 \%$ and $3.09 \pm$ $0.28 \%$ for BPRO and APRO1, respectively, and 4.76 $\pm 0.30 \%$ and $4.72 \pm 0.20 \%$ for BLAC and ALAC1, respectively.

We detected no milking session effect $(P>0.05)$ on monthly means of AFAT, APRO, ALAC, BFAT, BPO, or BLAC. For the evening milking session, however, the mean AFAT $(3.66 \%)$ was lower $(P=0.002)$ than the mean BFAT (3.80\%). The morning milking session had a similar mean AFAT $(3.67 \%)$ compared with BFAT $(3.69 \%)$ and no differences (all $P>0.05$ ) were observed between monthly means of APRO and BPRO and ALAC and BLAC. As an example, Figure 1 shows the agreement between Bentley and AfiLab measures of fat, protein, and lactose for the test-day milking on 
Table 4. Model parameters and fit statistics using different variables calculated from AfiLab (Afimilk, Kibbutz Afikim, Israel) observations to estimate Bentley (Bentley 2000 analyzer, Bentley Instruments Inc., Chaska, MN) fat; models were fit on the 2010 data and applied to the 2010 and 2011 data separately

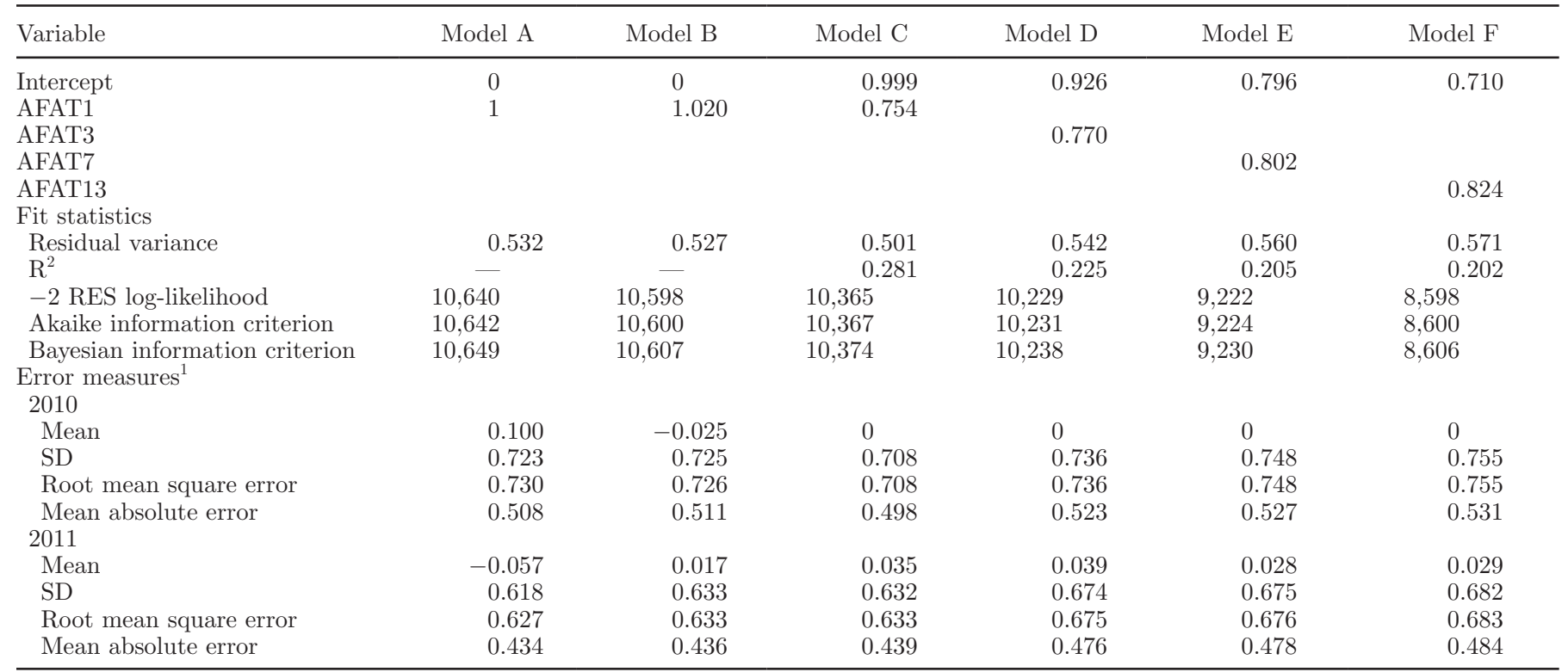

${ }^{1}$ Error calculated as AFATx - BFAT, where $\mathrm{x}$ is the percentage fat from 1, 3, 7, or 13 AfiLab observations around DHIA test day. BFAT $=$ percentage fat from the Bentley analysis.

December 12, 2011. Other test dates showed similar patterns.

The range of all BFAT observations was from 1.00 to $9.93 \%$. The corresponding AFAT1 observations for the 2 cows with BFAT equal to $1.00 \%$ were 3.01 and
2.57\%. The corresponding AFAT1 observations for the 5 cows with BFAT of $9.93 \%$ ranged from 3.89 to $5.86 \%$. The range of all BPRO observations was from 2.00 to 9.90\%. The corresponding APRO1 observation for the 1 cow with BPRO equal to $2.00 \%$ was $3.04 \%$, whereas

Table 5. Model parameters and fit statistics using different variables calculated from AfiLab (Afimilk, Kibbutz Afikim, Israel) observations to estimate Bentley (Bentley 2000 analyzer, Bentley Instruments Inc., Chaska, MN) protein; models were fit on the 2010 data and applied to the 2010 and 2011 data separately

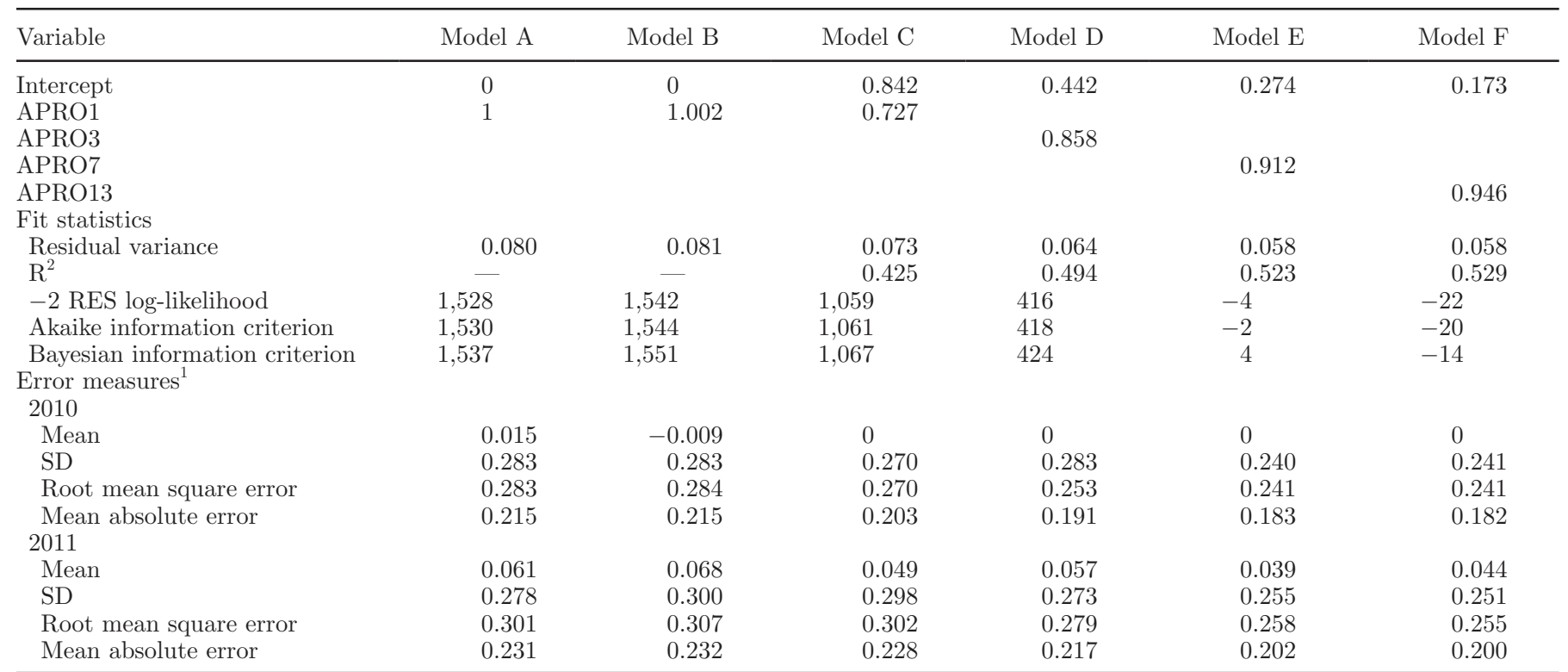

${ }^{1}$ Error calculated as APROx - BPRO, where $\mathrm{x}$ is the percentage protein from 1, 3, 7 or 13 AfiLab observations around DHIA test day. BPRO $=$ percentage protein from the Bentley analysis. 
Table 6. Model parameters and fit statistics using different variables calculated from AfiLab (Afimilk, Kibbutz Afikim, Israel) observations to estimate Bentley (Bentley 2000 analyzer, Bentley Instruments Inc., Chaska, MN) lactose; models were fit on the 2010 data and applied to the 2010 and 2011 data separately

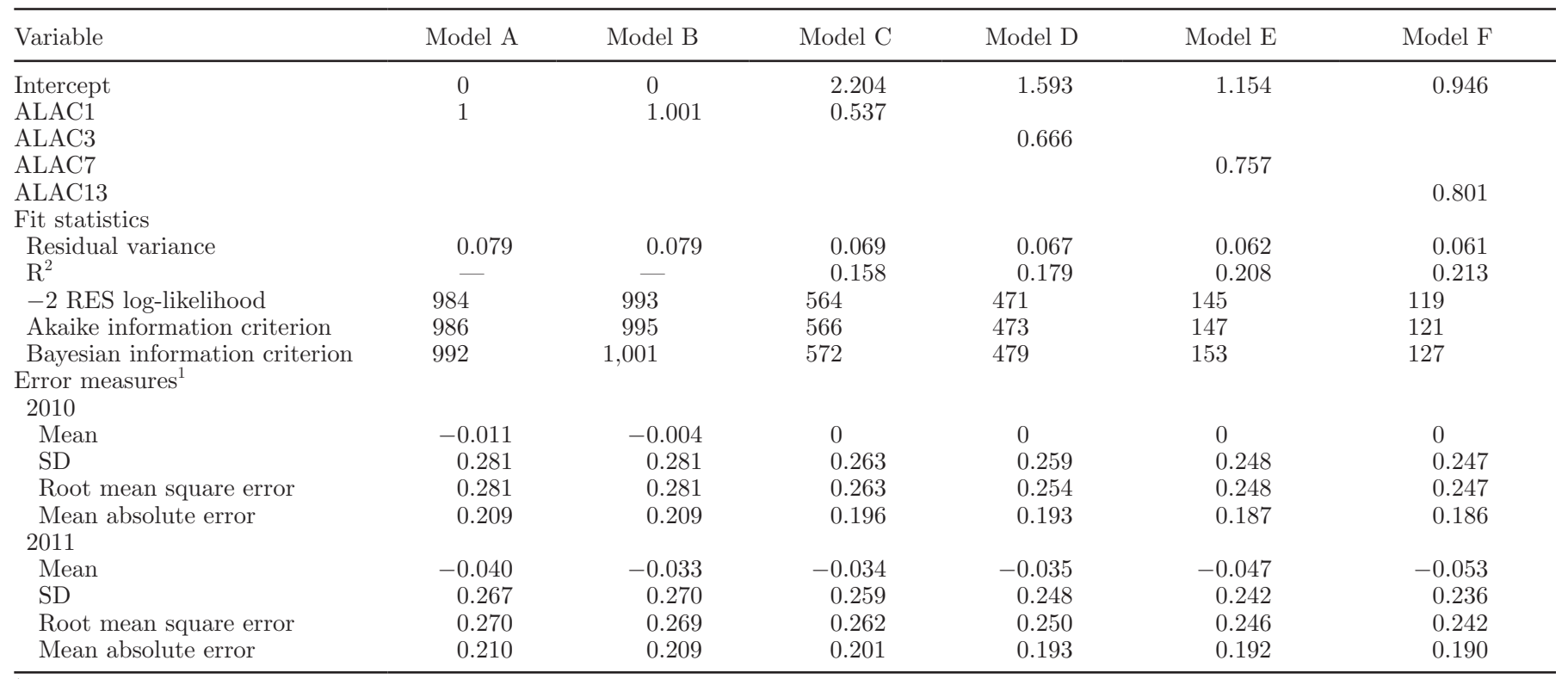

${ }^{1}$ Error calculated as ALACx - BLAC, where $\mathrm{x}$ is the percentage lactose from 1, 3, 7, or 13 AfiLab observations around DHIA test day. BLAC $=$ percentage lactose from the Bentley analysis.

the corresponding APRO1 observation for the 1 cow with BPRO equal to $9.93 \%$ was $4.86 \%$. The BLAC ranged from 2.09 to $5.46 \%$. The corresponding ALAC1 observation for the cow with BLAC equal to $2.09 \%$ was $2.31 \%$ and the corresponding ALAC1 observation for the cow with a BLAC equal to $5.46 \%$ was $4.68 \%$. The AFAT1 ranged from 1.43 to $7.16 \%$, APRO1 ranged from 1.55 to $4.86 \%$, and ALAC1 ranged from 1.38 to $5.73 \%$.

Regarding the AfiLab accuracy ranges, 165 (1.56\%) out of 10,571 BFAT observations were greater than $6.00 \%$, whereas $98(0.93 \%)$ were smaller than $2.00 \%$. For BPRO, $10(0.09 \%)$ of the 10,571 observations were greater than $5.00 \%$, whereas none was smaller than $2.00 \%$. These observations were maintained in the data set.

Table 2 shows the descriptive statistics of the differences between Bentley and AfiLab observations per cow on the 23 test dates. The maximum EFAT1, EPRO1, and ELAC1 in the data set were +3.94 percentage points $(\mathbf{P P}),+1.8 \mathrm{PP}$, and $+2.21 \mathrm{PP}$, respectively. The minimum EFAT1, EPRO1 and ELAC1 in the data set were $-6.04 \mathrm{PP},-5.4 \mathrm{PP}$, and $-2.92 \mathrm{PP}$, respectively.

The means \pm SD of the monthly means of EFAT1 $(\mathrm{n}=$ 23), EPRO1 $(\mathrm{n}=23)$, and ELAC1 $(\mathrm{n}=16)$ were -0.08 $\pm 0.12 \mathrm{PP}(P=0.007), 0.02 \pm 0.11 \mathrm{PP}(P=0.30)$, and $-0.02 \pm 0.08 \%(P=0.24)$, respectively. Therefore, only the fat estimate was biased. The monthly mean EFAT1 varied from -0.35 to $+0.11 \mathrm{PP}$. The range was -0.19 to $+0.29 \mathrm{PP}$ for EPRO1 and -0.23 to $+0.15 \mathrm{PP}$ for ELAC1. The means of the monthly means of EFAT3, EPRO3, and ELAC3 were $-0.06 \pm 0.16,+0.03 \pm 0.11$, and $-0.03 \pm 0.08 \mathrm{PP}$, respectively. The means of the monthly means of EFAT7, EPRO7, and ELAC7 were $-0.05 \pm 0.14,+0.01 \pm 0.09$, and $-0.03 \pm 0.09 \mathrm{PP}$, respectively, whereas the means of the monthly means of EFAT13, EPRO13, and ELAC13 were $-0.05 \pm 0.15$, $+0.01 \pm 0.10$, and $-0.03 \pm 0.09 \mathrm{PP}$, respectively.

The variation in the differences between the estimates of fat was greater than the variation in the differences between the estimates of protein and lactose. The means \pm SD of the monthly MAE for EFAT1, EPRO1, and ELAC1 were $+0.47 \pm 0.07,+0.22 \pm 0.04$, and $+0.21 \pm 0.03 \mathrm{PP}$. Mean \pm SD of within-test-day SD of EFAT1, EPRO1, and ELAC1 were $0.66 \pm 0.11$ $\mathrm{PP}, 0.27 \pm 0.03 \mathrm{PP}$, and $0.26 \pm 0.03 \mathrm{PP}$, respectively. Thus, the mean of the monthly SD in EFAT1 was, on average, 2.4 times as large as the mean of the monthly $\mathrm{SD}$ in EPRO1 and 2.5 times as large as the mean of the monthly SD in ELAC1. The SD of these withintest-date differences ranged from 0.48 to $0.87 \mathrm{PP}$ for EFAT1, from 0.23 to $0.34 \mathrm{PP}$ for EPRO1, and from 0.22 to $0.32 \mathrm{PP}$ for ELAC1. Because the biases were close to zero, the RMSE were only slightly larger than the SD.

Means \pm SD of the correlations were $0.59 \pm 0.09$ for fat, $0.67 \pm 0.04$ for protein, and $0.46 \pm 0.08$ for lactose. The monthly Pearson correlations ranged from 0.34 to 
0.72 for fat, from 0.57 to 0.75 for protein, and from 0.26 to 0.54 for lactose. All were different from zero $(P<$ 0.001). Although the correlations varied from test date to test date, no particular test date stood out.

The correlation between monthly mean BFAT (Table 1) and the monthly RMSE, MAE, mean, SD, and correlation (Table 2) for fat were $0.62,0.52,-0.46,0.58$, and -0.36 , respectively (all $P<0.05$ ), which indicate less agreement when the BFAT was greater. For the mean monthly BPRO and BLAC, however, the correlations with the 5 measures of agreement were not different from zero (all $P>0.05$ ).

Not surprisingly, the largest type-III F-values for EFAT1, EPRO1, and ELAC1 were BFAT, BPRO, and BLAC, respectively (Table 3 ). The BPRO was also a contributor $(P<0.001)$ for EFAT1 and ELAC1. The BLAC contributed $(P<0.001)$ to EPRO1 but not to EFAT1 $(P=0.36)$. Parity had only small effects on the estimation errors for fat and lactose, as evident from their F-values. Estimation errors for protein were not associated with parity $(P=0.11)$. Days in milk, fitted as a linear effect, contributed to EFAT1 and EPRO1 $(P<0.001)$ but not to ELAC1 $(P=0.51)$. Parlor stall contributed $(P<0.001)$ to the estimation errors of all 3 components. Of the 24 parlor stalls, the least squares means of 15 (EFAT1), 6 (EPRO1), and 13 (ELAC1) stalls were different $(P<0.01)$ from zero. These least squares means ranged from -0.18 to +0.05 PP for EFAT1, -0.04 to $+0.05 \mathrm{PP}$ for EPRO1, and -0.07 to 0.01 PP for ELAC1. Thus, no major deviations in specific AfiLab units were observed. Milk test date also contributed $(P<0.001)$ to the estimation errors of all 3 components. For EFAT1, the least squares means ranged from -0.22 to +0.17 for 23 test dates. For EPRO1, the range was -0.20 to $+0.18 \mathrm{PP}$. For ELAC1, the range was -0.20 to $+0.11 \mathrm{PP}$ for 16 test dates. The test date differences are shown in Table 2.

The AfiLab observations for fat, protein, and lactose were typically greater than the Bentley observations when the Bentley observations were low and vice versa. The 5 simple linear regression models (B to F) developed for each component from the 2010 data had only small reductions in estimation errors compared with the default model (A). Results are shown in Table 4 for fat, Table 5 for protein, and Table 6 for lactose.

The intercept $\mathrm{b}_{0}$ was forced to be 0 in model $\mathrm{B}$ and therefore the $\mathrm{R}^{2}$ was much larger than in models $\mathrm{C}$ to $\mathrm{F}$, where the intercept was estimated. Hence, the $\mathrm{R}^{2}$ values for models $\mathrm{A}$ and $\mathrm{B}$ were not reported. For all models $\mathrm{C}$ to $\mathrm{F}$, the AfiLab coefficient $\mathrm{b}_{1}$ was $<1$. The estimated value was greater than the original AfiLab value when the AfiLab value $<\mathrm{b}_{0} /\left(1-\mathrm{b}_{1}\right)$. For example, the regression equation of model $\mathrm{C}$ for protein estimated a higher percentage protein in the milk than
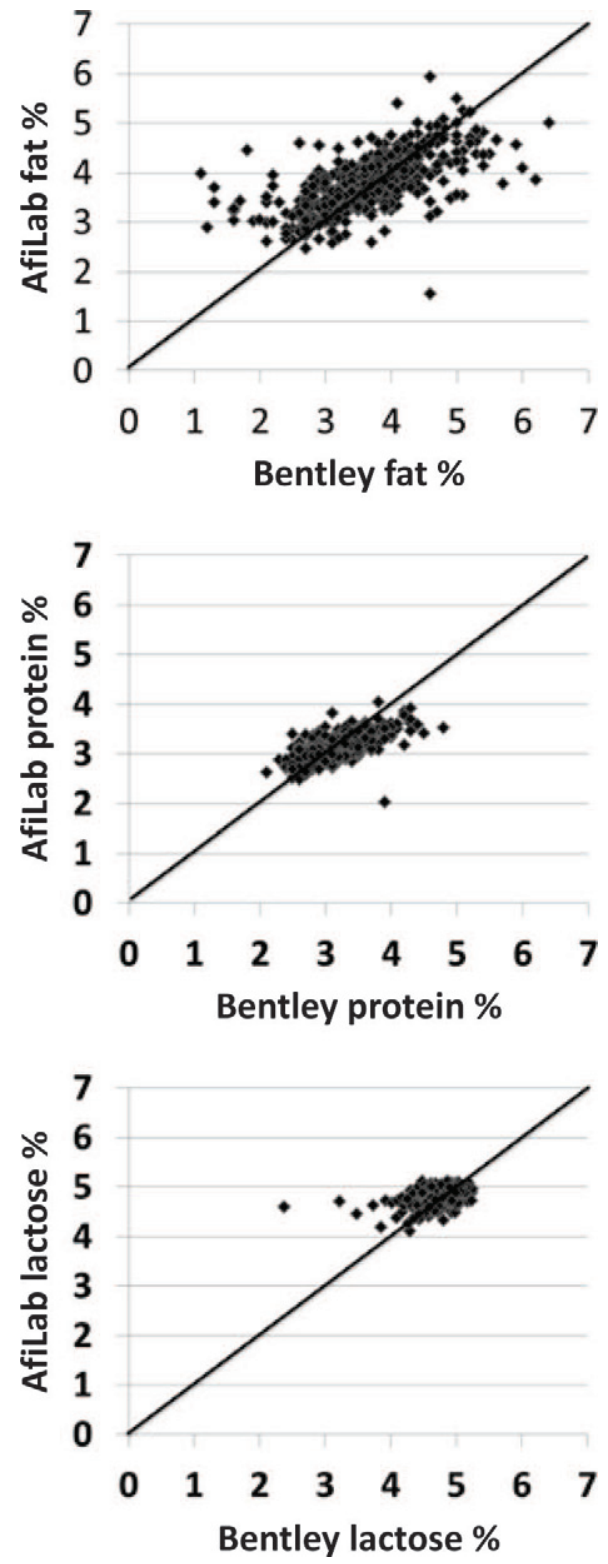

Figure 1. Scatter plots for fat, protein, and lactose observations measured for all sampled cows on the DHIA test date of December 12, 2011, by the Bentley (Bentley 2000 analyzer, Bentley Instruments Inc., Chaska, MN) and AfiLab (Afimilk, Kibbutz Afikim, Israel) analyzers.

APRO1 when the APRO1 $<0.7272 /(1-0.8424)=$ $4.61 \%$.

As judged by the smallest RMSE, MAE, and SD (Table 4 and Figure 2), the best estimator for BFAT was model $\mathrm{C}$ when estimated on the 2010 data, but model A (the original AFAT1) was the best estimator for the 2011 BFAT data. Therefore, the equations with AFAT3, AFAT7, or AFAT13 did not improve the estimations. For protein (Table 5), model F (APRO13) was the best estimator for both the 2010 and 2011 data, as judged by SD, MAE, RMSE, and correlation. The 
RMSE for model $\mathrm{F}$ for the 2011 data was reduced by $15 \%$ compared with model A, the original APRO1. In addition, the measures APRO3 (model D) and APRO7 (model E) resulted in better estimations than model A. For lactose (Table 6), the equation with ALAC13 (model F) also resulted in the smallest RMSE, MAE, and SD, and typically the greatest correlation, for both the 2010 and 2011 data. The reduction in RMSE was $10 \%$ compared with ALAC1 (model A) for the 2011 data.

The final analysis investigated whether the milk components of certain cows were typically overestimated or underestimated by AfiLab, independent of the level of these components. Model $\mathrm{C}$ was used to estimate the milk components. Of the 854 cows with at least 2 observations, $47(5.50 \%)$ had mean estimation errors different from zero $(P<0.05)$. Of these 47 observations, $17(1.99 \%)$ were underestimated and $30(3.51 \%)$ were overestimated. For protein, of the 827 cows with at least 2 observations, $40(4.84 \%)$ had a mean estimation error different from zero $(P<0.05)$. Of these 40 , $24(2.90 \%)$ cows were underestimated and $16(1.93 \%)$ cows were overestimated. For lactose, of the 817 cows with at least 2 observations, $134(16.40 \%)$ had mean estimation errors different from zero $(P<0.05)$. Of these 134 cows, $88(10.77 \%)$ cows were underestimated and $46(5.63 \%)$ were overestimated by AfiLab. Hence, some evidence suggested that AfiLab systematically underestimated lactose components for certain cows.

\section{DISCUSSION}

This study compared observations of fat, protein, and lactose obtained with AfiLab real-time milk analyzers for individual cow milkings with the observations collected on routine monthly DHIA test days and analyzed with the Bentley 2000 milk analyzers in the laboratory. The level of agreement varied substantially from test day to test day. The monthly means of EFAT1 and EPRO1 ranged from -0.35 to $0.11 \mathrm{PP}$ and from -0.19 to $0.29 \mathrm{PP}$, respectively. In comparison, Arazi et al. (2012) reported smaller ranges of -0.05 to 0.28 $\mathrm{PP}$ and 0.01 to $0.05 \mathrm{PP}$ for fat and protein estimation errors, respectively, for approximately 180 milkings of 800 cows.

The true composition of the analyzed milk in this study is not known. The Bentley method is designed to closely agree with the analyzed milk, however. The MIR milk analysis performed by the Bentley is a standard method in milk component testing (Barbano and Lynch, 2006). Accuracy of MIR analysis of milk is affected by instrument factors, quality of reference chemistry, characteristics of the calibration sample set, and individual milk sample composition factors
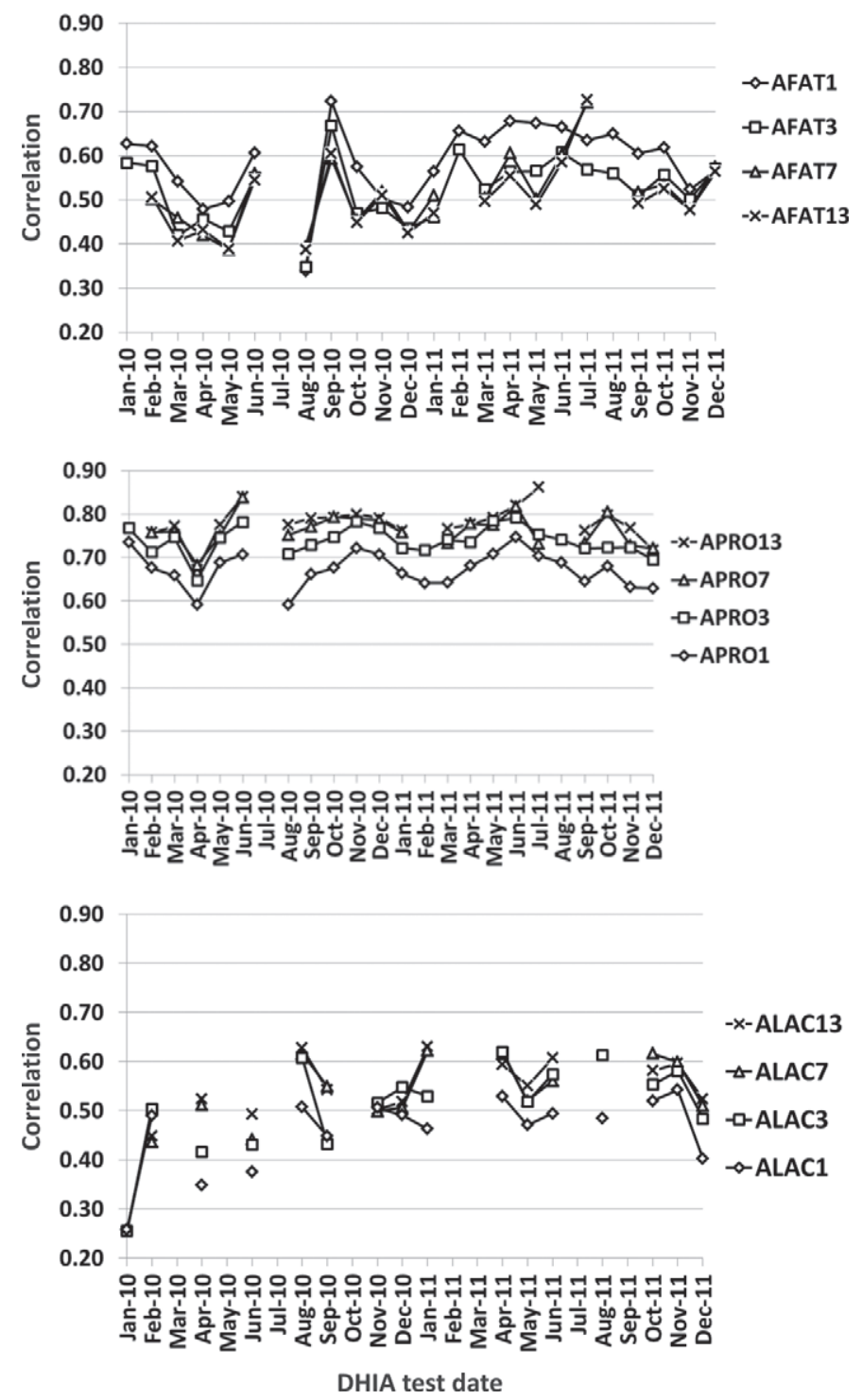

Figure 2. Pearson correlations for Bentley (Bentley 2000 analyzer, Bentley Instruments Inc., Chaska, MN) fat, protein, and lactose with multiple observations of AFATx, APROx and ALACx, where AFAT, $\mathrm{APRO}$, and ALAC are fat, protein, and lactose observations from AfiLab (Afimilk, Kibbutz Afikim, Israel), respectively, and $\mathrm{x}$ is consecutive $1,3,7$, or 13 observations around the DHIA test-day milking.

(Kaylegian et al., 2006). The MIR method is secondary because it must be frequently calibrated with reference samples from primary chemical methods. The accuracy of MIR analyzers used by DHIA is high, with differences between reference and MIR values of $<0.05 \%$ for fat, protein and lactose (Etzion et al., 2004; Kaylegian et al., 2006). The AfiLab system is based on NIR milk analysis, which is less sensitive than the MIR method although good accuracy may still be obtained (Tsenkova et al., 2000). The AfiLab equipment is also made with less expensive components to make the analyzer commercially feasible, which may compromise accuracy. 
Some evidence exists that the accuracy of milk component testing by AfiLab is cow-specific, except for the slight bias when components are low or high (Tsenkova et al., 2000). Differences in protein measures could be attributed to the content or physical structure of true proteins and differences in the ratio of true protein to nonprotein nitrogen in the milk sample (Tsenkova et al., 2000). Some of the variability in lactose observations may be due to the concentration of sodium, potassium, and chloride ions that are negatively correlated to lactose. Some evidence existed in our study that lactose was underestimated or overestimated more often than expected within cow $(16 \%$ had $P<0.05$, where the expectation was that $5 \%$ would have $P<$ 0.05 by random chance).

Overestimation of lower milk components and underestimation of greater milk components reduces the probability that real changes are quickly detected. For example, a decrease in lactose may be a sign of emerging mastitis (Auldist et al., 1995; Svennersten-Sjaunja et al., 1997), and early detection of a change in lactose might be useful.

Despite the high accuracy of the Bentley method, the validity of the DHIA measures was questioned by herd management for several test days, especially when the mean DHIA observations for fat were greater than expected. Figure 3 shows the monthly mean lactose, fat, and protein percentages, weighted by each cow's milk yield at the test-day milking for the Bentley and AfiLab methods and the observations for the shipped bulk tanks that included the test-day milkings. Bulk tank milk was shipped approximately twice every $3 \mathrm{~d}$ and analyzed with the same Bentley machine as the DHIA milk samples. The difference between the weighted Bentley observations and the bulk tank observations could be substantial. The differences between the mean AfiLab and bulk tank observations were often smaller than the differences between the mean Bentley and bulk tank observations. Large differences between AfiLab and bulk tank components were observed on test dates January 17 and February 7, 2011, for lactose and protein, and March 13 and April 11, 2011, for fat. Larger differences with the Bentley fat observations were observed in the spring of 2010 and for test dates November 15, 2010, December 13, 2010, and January 17, 2011. Comparisons of DHIA and payment test (bulk tank) results for fat usually do not vary by more than 0.2 PP (Dairy Practices Council, 2001). As a consequence of the perceived invalidity of DHIA test results, AfiLab was not zero-set after the test dates of May 17, 2010, and January 17, 2011.

Another source of less-than-perfect agreement may be milk sampling. Milk components vary during the course of milking, with fat increasing and protein and lactose decreasing during milking in wk 4 of lactation (Ontsouka et al., 2003). AfiLab analyses every $200 \mathrm{~mL}$ of harvested milk and presents 1 average value after the cow's milking. The milk sampled by DHIA may be different from the analyzed milk (often analyzed the day after collection) due to inconsistencies in milk col-

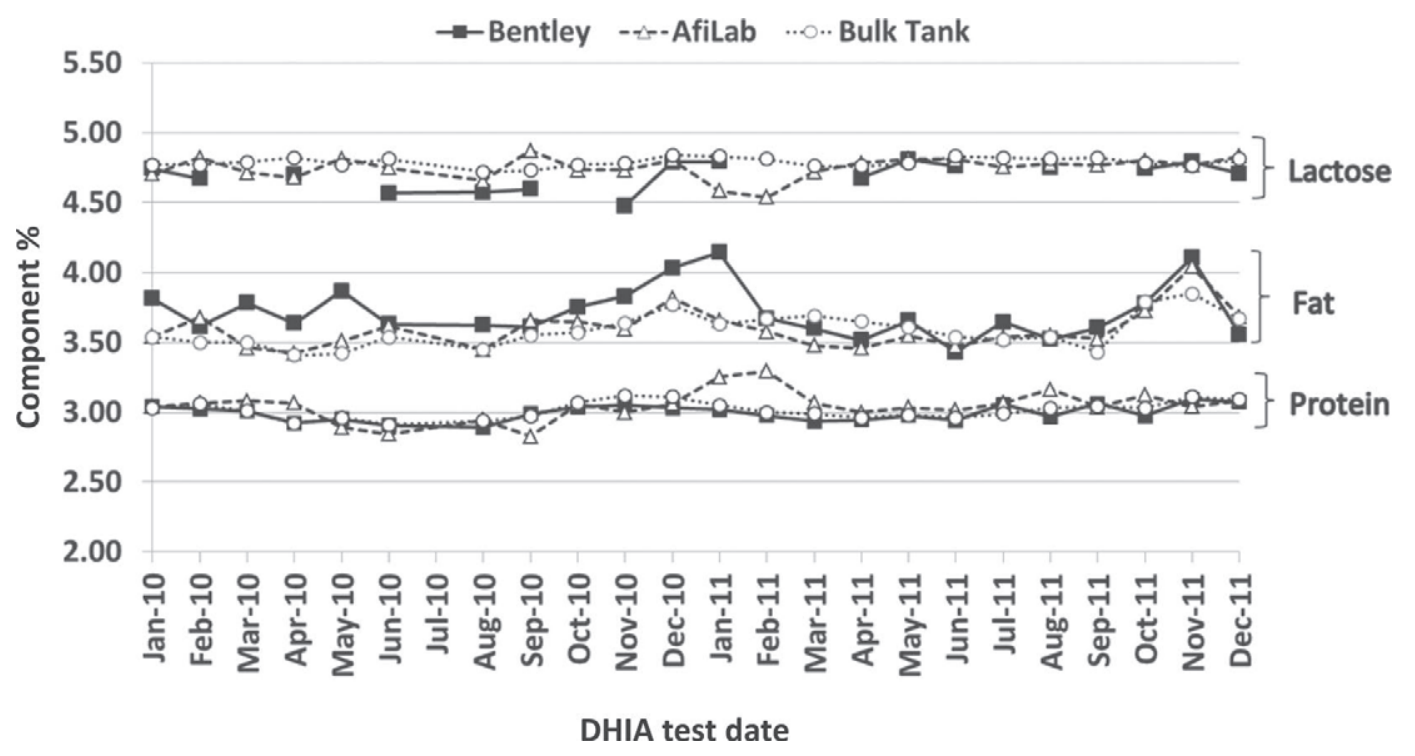

Figure 3. Weighted means of lactose, protein, and fat obtained from the Bentley (Bentley 2000 analyzer, Bentley Instruments Inc., Chaska, MN), AfiLab (Afimilk, Kibbutz Afikim, Israel), and bulk tank analyses on 23 DHIA test-days. The bulk tank data included the milking of the DHIA test and 1 or 2 additional milking sessions. The Bentley and AfiLab weighted mean components were calculated from each cow's individual components and her milk yield at the DHIA test-day milking. 
lection, storage, or transportation (Coleman and Moss, 1989). For example, violent shaking of the DHIA milk sample increases the amount of free fatty acids in the milk, which causes a decreased fat test at the laboratory. Such inconsistencies might explain the unexpected DHIA results for certain months, as seen in Table 1. Carryover from one cow to the next in the same parlor stall as a result of human error may also decrease agreement (Løvendahl and Bjerring, 2006).

In 2011, 372 milk samples collected during 14 sequential milkings from 30 cows at the University of Florida's Dairy Unit were split in half and sent to 2 laboratories, including the one used in our study, which used either the Bentley or the Foss MilkoScan (Foss, Eden Prairie, MN) for analysis of milk components. Milk fat observations were within $0.1 \mathrm{PP}$ of each other and the correlation for the split fat observations was 0.986 (C. R. Staples, University of Florida, Gainesville, personal communication). Therefore, lack of agreement is likely the result of milk sampling and not the techniques used in the DHIA laboratory.

The AfiLab results are dependent on proper cleaning of the milking equipment. Routine cleaning was performed in agreement with Afimilk guidelines but may have occasionally deviated. The lower AfiLab lactose results on the test dates of April 19, 2010, January 17, 2011, and February 7, 2011, suggest a cleaning issue. Poor agreement for lactose between AfiLab and DHIA is typically caused by insufficient washing of the milking equipment. When agreement for protein and lactose is good but agreement for fat is poor, it is usually due to sampling practices that deviate from the official DHIA procedures (A. Arazi, Afimilk, Israel, personal communication).

In addition, several of the 24 stalls showed a small bias in the AfiLab results. Furthermore, zero-setting of AfiLab with the Bentley results was performed on average $13 \mathrm{~d}$ after the DHIA test, which is later than recommended. The agreement between AfiLab and the Bentley observations is likely lowest just before the zero-setting because the last zero-setting would have been based on DHIA data obtained almost 45 d previously.

Collectively, multiple reasons might explain the lessthan-perfect agreement between AfiLab and Bentley observations of fat and protein. Means of multiple AfiLab observations for protein and lactose and simple regression equations increased the agreement slightly (Tables 5 and 6 ). The accuracy of fat estimations was not improved by combining multiple AfiLab observations, likely because the fat content varies more from day to day (milking to milking) within cow than do protein (Syrstad, 1977; Quist et al., 2008) and lactose (Forsbäck et al., 2010). Other combinations of multiple observations may improve accuracy further. However, the weighted means of AfiLab observations, with weights using the AMY, did not improve the accuracy of estimation compared with the best models in Tables 4,5 , and 6 (results not shown).

Estimation errors for fat were, on average, approximately 2.5 times greater than estimation errors for protein and lactose. Near-infrared methods to measure fat are accurate (Aernouts et al., 2011). It is likely that the larger estimation errors for fat are primarily related to larger day-to-day or within-milking variation of fat content within a cow's milk and not measurement error.

Collectively, the AfiLab observations were slightly more accurate than random draws from the distribution for each milk component for the herd (Table 1) as evidenced by smaller SD (Tables $2,4,5$, and 6 ) and positive correlations. An alternative simple estimator is to use the previous month's Bentley observation to estimate the observation for the current month for the same cow. Using the Bentley observations from this study, the means $\pm \mathrm{SD}$ of the month-to-month correlations for fat $(\mathrm{n}=22)$, protein $(\mathrm{n}=22)$, and lactose (n $=9$ ) were $0.42 \pm 0.08,0.71 \pm 0.08$, and $0.57 \pm 0.17$, respectively. The SD of the month-to-month differences for fat, protein, and lactose were $0.85 \pm 0.13 \mathrm{PP}, 0.28$ $\pm 0.05 \mathrm{PP}$, and $0.32 \pm 0.11 \mathrm{PP}$, respectively. These agreement statistics are slightly worse than those for AfiLab, except for the correlations for protein and lactose, which were lower for AfiLab. The capabilities of the AfiLab system to estimate SCC are still being improved and therefore were not of interest in this study.

For various management purposes such as the ranking of cows for culling decisions, evaluation of different treatment effects, or individual precision feeding (Maltz et al., 2009, 2013), it may be more relevant to know the average or sum of a cow's milk composition for a period longer than 1 milking. Given the day-to-day variation in milk components, especially fat (Syrstad, 1977; Quist et al., 2008; Forsbäck et al., 2010), the milk components measured in just 1 milking per month may not be very representative of the milk produced during that entire month or even a shorter period during that month, especially in early lactation, as described by Maltz et al. (2009). The combination of much more frequently but less accurately analyzed milk components, such as averaging all AfiLab observations obtained per milking over a period for a cow, may give a more representative measure of a cow's longer term milk composition than a DHIA sample taken once per month. This may be especially true for fat, because a component with a greater day-to-day variation needs more frequent sampling when used as a diagnostic tool and for management decisions (Forsbäck et al., 2010). Further study should 
determine the value of more frequent sampling, even if the measurement error is greater, and will help determine the value of real-time milk analyzers in practice.

\section{CONCLUSIONS}

Agreement, as measured by the average correlations between Bentley and AfiLab measures of fat (0.59), protein (0.67), and lactose (0.46), was judged to be moderate. AfiLab observations were helpful estimators of DHIA observations. A combination of AfiLab observations for protein and lactose around the DHIA test day resulted in slightly better agreement. A significant DHIA test-day effect existed, casting doubt about the composition of the milk analyzed by DHIA on some days, which might have resulted in poorer agreement. An analysis of sampling frequency may provide further insight into the usefulness of real-time milk analyzers in practice, even when their accuracy is lower than official DHIA methods.

\section{ACKNOWLEDGMENTS}

We thank the staff of the University of Florida Dairy Unit, especially Eric Diepersloot, for their help collecting the data. We also thank Afimilk (Kibbutz Afikim, Israel) for providing the AfiLab analyzers.

\section{REFERENCES}

Aernouts, B., E. Polshin, J. Lammertyn, and W. Saeys. 2011. Visible and near-infrared spectroscopic analysis of raw milk for cow health monitoring: Reflectance or transmittance? J. Dairy Sci. 94:5315-5329.

Arazi, A., N. Pinski, T. Schcolnik, E. Aizinbud, G. Katz, and E. Maltz. 2012. Innovations arising from applied research on a new on-line milk analyzer and a behavior meter. Pages 34-43 in New Trends for Innovation in the Mediterranean Animal Production. Vol. 129. Wageningen Academic Publishers, Wageningen, the Netherlands.

Auldist, M. J., S. Coats, G. L. Rogers, and G. H. McDowell. 1995 Changes in the composition of milk from healthy and mastitic dairy cows during the lactation cycle. Aust. J. Exp. Agric. $35: 427-436$.

Barbano, D. M., and J. M. Lynch. 2006. Major advances in testing of dairy products: Milk component and dairy product attribute testing. J. Dairy Sci. 89:1189-1194.

Coleman, D. A., and B. R. Moss. 1989. Effects of several factors on quantification of fat, protein, and somatic cells in milk. J. Dairy Sci. 72:3295-3303.

Dairy Practices Council. 2001. Guidelines for fat test variations in raw milk (DPC 32). 3rd reviewed ed. Dairy Practices Council, Keyport, NJ. Accessed Oct. 17, 2013. http://www.mqtlabs.com/sites/ default/files/page/attachments/Fat_Tests_Variations_Oct_2001_ DPC032.pdf.

De Vries, A., and S. Feleke. 2008. Prediction of future uniform milk prices in Florida Federal Milk Marketing Order 6 from milk futures markets. J. Dairy Sci. 91:4871-4880.

Duffield, T. F., D. F. Kelton, K. E. Leslie, K. D. Lissemore, and J. H. Lumsden. 1997. Use of test day milk fat and milk protein to detect subclinical ketosis in dairy cattle in Ontario. Can. Vet. J. $38: 713-718$.
Etzion, Y., R. Linker, U. Cogan, and I. Shmulevich. 2004. Determination of protein concentration in raw milk by mid-infrared Fourier transform infrared/attenuated total reflectance spectroscopy. J. Dairy Sci. 87:2779-2788.

Forsbäck, L., H. Lindemark-Månsson, A. Andrén, M. Åkerstedt, L. Andrée, and K. Svennersten-Sjaunja. 2010. Day-to-day variation in milk yield and milk composition at the udder-quarter level. J. Dairy Sci. 93:3569-3577.

Kaylegian, K. E., J. M. Lynch, G. E. Houghton, J. R. Fleming, and D. M. Barbano. 2006. Modified versus producer milk calibration: Mid-infrared analyzer performance validation. J. Dairy Sci. 89:2833-2845.

Løvendahl, P., and M. A. Bjerring. 2006. Detection of carryover in automated milk sampling equipment. J. Dairy Sci. 89:3645-3652.

Maltz, E., A. Antler, I. Halachmi, and Z. Schmilovitch. 2009. Precision concentrate rationing to the dairy cow using on-line daily milk composition sensor, milk yield and body weight. Pages $17-23$ in Proc. 4th Euro. Conf. Precision Livestock Farming, Wageningen, the Netherlands. Wageningen Academic Publishers, Wageningen, the Netherlands.

Maltz, E., L. F. Barbosa, P. Bueno, L. Scagion, K. Kaniyamattam, L. F. Greco, A. De Vries, and J. E. P. Santos. 2013. Effect of feeding according to energy balance on performance, nutrient excretion and feeding behavior of early lactation dairy cows. J. Dairy Sci. 96:5249-5266.

Murphy, M., M. Åkerlind, and K. Holtenius. 2000. Rumen fermentation in lactating cows selected for milk fat content fed two forage to concentrate ratios with hay or silage. J. Dairy Sci. 83:756-764.

Ontsouka, C. E., R. M. Bruckmaier, and J. W. Blum. 2003. Fractionized milk composition during removal of colostrum and mature milk. J. Dairy Sci. 86:2005-2011.

Pavel, E. R., and C. Gavan. 2011. Seasonal and milking to milking variations in cow milk fat, protein and somatic cell counts. Notulae Scientia Biologicae 3:20-23.

Quist, M. A., S. J. LeBlanc, K. J. Hand, D. Lazenby, F. Miglior, and D. F. Kelton. 2008. Milking-to-milking variability for milk yield, fat and protein percentage, and somatic cell count. J. Dairy Sci. 91:3412-3423.

Rotz, C. A., C. U. Coiner, and K. J. Soder. 2003. Automatic milking systems, farm size, and milk production. J. Dairy Sci. 86:41674177.

Schmilovitch, Z., A. Mizrach, A. Hoffman, H. Egozi, and Y. Fuchs. 2000a. Determination of mango physiological indices by near-infrared spectrometry. Postharvest Biol. Technol. 19:245-252.

Schmilovitch, Z., I. Shmulevich, A. Notea, and E. Maltz. 2000b. Near infrared spectrometry of milk in its heterogeneous state. Comput. Electron. Agric. 29:195-207.

Studer, E. 1998. A veterinary perspective of on-farm evaluation of nutrition and reproduction. J. Dairy Sci. 81:872-876.

Svennersten-Sjaunja, K., L. O. Sjaunja, J. Bertilsson, and H. Wiktorsson. 1997. Use of regular milking records versus daily records for nutrition and other kinds of management. Livest. Prod. Sci. 48:167-174.

Syrstad, O. 1977. Day-to-day variation in milk yield, fat content, and protein content. Livest. Prod. Sci. 4:141-151.

Tsenkova, R., S. Atanassova, K. Itoh, Y. Ozaki, and K. Toyoda. 2000. Near infrared spectroscopy for biomonitoring: Cow milk composition measurement in a spectral region from 1,100 to 2,400 nanometers. J. Anim. Sci. 78:515-522.

Tsenkova, R., S. Atanassova, K. Toyoda, Y. Ozaki, K. Itoh, and T. Fearn. 1999. Near-infrared spectroscopy for dairy management: Measurement of unhomogenized milk composition. J. Dairy Sci. 82:2344-2351.

Wiggans, G. R. 1986. Procedures for calculating lactation records. Accessed Oct. 22, 2013. http://aipl.arsusda.gov/publish/dhi/ handbook/calclac.pdf.

Wiggans, G. R. 1994. Meeting the needs at the national level for genetic evaluation and health monitoring. J. Dairy Sci. 77:1976-1983. 